\title{
INOCULATED BROAD BEANS (VICIA FABA) AS A PRECROP FOR SPRING ONIONS (ALLIUM CEPA)
}

\author{
Laila Dubova, Alise Šenberga, Ina Alsiṇa \\ Latvia University of Agriculture \\ Laila.Dubova@1lu.lv
}

\begin{abstract}
The agronomic role of legumes in cropping systems is well understood with the respect to $\mathrm{N}_{2}$ fixation, mechanisms of precrop effects, and environmental impacts. The combined inoculation and tripartite symbiosis between leguminous plants, Rhizobium spp. and vesicular-arbuscular mycorrhizal fungi has been the subject of intensive research. Less attention has been paid to their effects on subsequent crops. Pot experiments were carried out in the greenhouse of Latvia University of Agriculture in 2015 and 2016. Soil used for this experiment was taken from the previous trial, where broad beans (Vicia faba var. major Harz.) were grown. Bean seeds, depending on the variant, were inoculated with rhizobia bacteria or mycorrhiza fungi, or the mixture of both microorganisms. Onions were grown as a subsequent crop. During the experiment, fresh and dry weight of onion leaves was determined. Onion root mycorrhizal colonization frequency and arbuscule abundance in the onion root system were determined. The activity of soil microorganisms was determined by soil respiration intensity. Results showed that the use of microsymbionts increased the subsequent onion leaf harvest in 2014 by $2.3 \%$ and in 2015 by $9.5 \%$. In 2015 the highest increase of onion leaf yield was detected in variants were rhizobia strain RP023 was used. Rhizobia strain RV407 gave a positive effect only in combination with mycorrhiza fungi. Precrop treatment with mineral nitrogen fertilizer increased the onion yield in both years - by 12.4 and $14.3 \%$, respectively. In all treatments, a decrease in dry matter content was observed. The highest incidence of mycorrhiza fungi structures was detected under mycorrhiza treatment. Tripartite symbiosis promoted the soil respiration rate.
\end{abstract}

Key words: legumes, crop rotation, Rhizobium sp., mycorrhiza fungi, soil respiration.

\section{Introduction}

Beans, as an important part of a sustainable agriculture, should be included in crop rotations in intensive agriculture to diversify now simplified crop rotations (Köpke \& Nemecek, 2010). The agronomic precrop benefits of legumes can be divided into a 'nitrogen effect' component and 'break crop effect' component (Stagnari et al., 2017). The 'nitrogen effect' component is a result of acquiring nitrogen via symbiotic nitrogen fixation. The second one ('break crop effect') includes diverse benefits, such as improvements of soil organic matter and structure. The symbiotic root-fungal association increases the uptake of less mobile nutrients (Ortas et al., 2001), essentially phosphorus $(\mathrm{P})$, but also micronutrients like zinc $(\mathrm{Zn})$ and copper $(\mathrm{Cu})$. In addition, the symbiosis has also been reported to influence water uptake as well as reduced pressure from diseases and weeds (Nuruzzaman et al., 2005; Köpke \& Nemecek, 2010; Preissel et al., 2015; Stagnari et al., 2017).

Faba beans are mostly grown as a field crop, with cereals as the subsequent crop. But broad beans are mostly grown as horticulture crop, hence the subsequent crop can be any vegetables. To promote symbiotic nitrogen fixation, legumes are mostly inoculated with Rhizobium bacteria. Mycorrhizal fungi are obligate symbionts that form mutualistic relationships with plant roots known as a mycorrhiza. Mycorrhizal fungi receive carbon from their host plants in exchange for nutrient transfer to the roots, which benefits plant growth. Therefore arbuscular mycorrhizal fungi (AMF) can be integrated in the soil management to achieve low-cost sustainable agricultural systems (Hooker \& Black, 1995). The combined inoculation and tripartite symbiosis between leguminous plants, Rhizobium spp. and vesiculararbuscular mycorrhizal (VAM) fungi has been the subject of intensive research (Ames \& Bethlenfalvay, 1987; Abd-Alla et al., 2014).

The microorganism, introduced in the soil as an inoculum, affects not only the inoculated plants but it remains in the soil for the next growing season and can also affect the subsequent crops. While rhizobia are forming symbiosis exclusively with legumes, the mycorrhizal fungi have a broader host range. More and more are revealed VAM fungi host specialization than previously stated (Heijden van der \& Scheublin 2007). Although the presence of mycorrhizal fungi are detectable in roots of majority of the plants, the impact on crop growth and yield may vary. Specific and non-specific relationships between symbionts have been found. This means that the VAM genotypes have a different impact on plant biomass formation and nutrient uptake. Biotic and abiotic factor interaction (eg., plant density, photosynthetic rate, the available mineral elements) significantly influence benefits obtained by host plants. These crops can potentially increase yields of subsequent cereal crops (Munkvold et al., 2004; Koch et al., 2006). Plantmicrobe interactions influence soil microbiological activity. Plants are able to influence the composition and activity of microbial community around their root systems through the selective exudation of specific carbohydrates, carboxylic and amino acids, and 


\section{Bean seeds inoculation variants}

\begin{tabular}{|l|l|}
\hline \multicolumn{1}{|c|}{ Label of variants } & \\
\hline $\mathrm{K}$ & control without any treatment \\
\hline RP023 & Rhizobium sp. strain RP0233 \\
\hline RV407 & Rh. sp. strain RV407 \\
\hline $\mathrm{M}$ & mycorrhiza fungi \\
\hline RP023M & Rh. sp. strain RP023 and mycorrhiza fungi \\
\hline RV407M & Rh. sp. strain RV407Mand mycorrhiza fungi \\
\hline KN & added mineral nitrogen fertilizers, without microorganism treatment \\
\hline
\end{tabular}

these microbial communities can be cultivar-specific. Microorganisms in the rhizosphere can themselves induce root exudation responses in plants or initiate changes in root biochemistry (Sturz \& Christie, 2003; Verbruggen \& Kiers, 2010).

The mycorrhiza can influence onion growth beneficially. Onions have an insufficient, mostly unbranched, shallow root system, almost without root hairs. Therefore, mycorrhiza are important for such plants to improve uptake of nutrients and growth (Shuab et al., 2014).

The aim of the experiment was to compare the effect of different broad bean seed inoculation variants on the subsequent crop.

\section{Materials and Methods}

Pot experiments with onions were carried out in the greenhouse at the Institute of Soil and Plant Sciences, Latvia University of Agriculture in 2015 and 2016. The onion sets were planted in pots where broad beans (Vicia faba var. major Harz.) were grown in 2014 and 2015. For pot experiments, loamy sand soil was used. Soil analyses were conducted at the Institute of Biology, Latvia University before experiments with broad beans and characterized by $\mathrm{pH} \mathrm{KCl}$ 7.6, Ec $0.73 \mathrm{mS} \mathrm{cm}^{-1}$ and mineral element content in $1 M \mathrm{HCl}$ solution (mg L-1): N-78, P-523, K-170, Ca-161450, Mg-3850, S-65, Fe-1920, Mn-170, Zn-10.5, Cu-6.5, Mo-0.08, B-0.4.

Broad bean seeds, depending on the variant, were inoculated with Rhizobia bacteria or mycorrhiza fungi, or the mixture of both microorganisms (Table 1). At the end of vegetation period, the plant shoots were harvested but roots left in the soil as postharvest residues.

Onions were grown as a subsequent crop after broad beans. Five onions were planted in $5 \mathrm{~L}$ pots. Experiment was carried out in four replications.

Onions were fertilized only once to adjust the nutrients taken out by the precrop. They were fertilized with Kristalon ${ }^{\mathrm{TM}} 13+05+26+3+$ micro- dose $0.8 \mathrm{~g}$ per vegetation pot (respectively $20 \mathrm{~g} \mathrm{~m}^{-2}$ ) a week after onion planting.
In the first year (2015) experiment started at the beginning of February. In the second year (2016) experiment started later - in April (Table 2). Additional illumination $\left(286.5 \mu \mathrm{mol} \mathrm{m} \mathrm{m}^{-2} \mathrm{~s}^{-1}\right)$ with 12 hours photoperiod was used in 2015. Air temperature during greenhouse experiment during the day was between $15-25^{\circ} \mathrm{C}$, but in the night $8-15^{\circ} \mathrm{C}$.

The first leaf yield samples were collected 20 days after planting, further samples were collected once per week. In total, onion leaves were collected 5 times every year. Each time 5 leaves from one pot were collected (in total 20 leaves from each variant) to determine fresh and dry (dried 2 days at $60^{\circ} \mathrm{C}$ ) weight.

Onion root mycorrhizal colonization frequency and arbuscule abundance in the onion root system was determined at the end of experiment. The activity of soil microorganisms was determined by soil respiration intensity. For determination of soil basal respiration intensity, modified method described by Pell, Stenström, \& Granhall, (2005) was used. Briefly - soil respiration was determined by placing $50 \mathrm{~g}$ of field-moist soil and a beaker containing $5 \mathrm{~mL}$ of $0.1 \mathrm{M} \mathrm{KOH}$ solution into a $500 \mathrm{~mL}$ jar; the jar was sealed and placed in the dark at $30^{\circ} \mathrm{C}$ for 24 hours. Afterwards, the $\mathrm{KOH}$ solution was removed and titrated with $0.1 \mathrm{M} \mathrm{HCl}$ to determine the amount of $\mathrm{CO}_{2}$ evolved with the soil microbial respiration. The soil moisture was determined by drying the sample for 24 hours at $105{ }^{\circ} \mathrm{C}$.

For assessment of onion root mycorrhizal colonization, 30 root fragments from each pot were randomly collected. The roots were stained according to Vierheilig et al., (1998). The sampled roots were cleared by soaking in $10 \% \mathrm{KOH}$ for $24 \mathrm{~h}$ (room temperature) and then rinsed several times with tap water. Cleared roots were boiled for $3 \mathrm{~min}$ in a $5 \%$ ink-vinegar solution. Roots were destained by rinsing with tap water (acidified with a few drops of vinegar). After staining, the roots were cut into $1 \mathrm{~cm}$ sections, mounted onto slides and analysed. Absolute mycorrhizal colonization and arbuscule/ vesicule richness were assessed. Onion root mycorrhizal colonization frequency and arbuscule abundance in 


\section{Design of experiments}

\begin{tabular}{|c|c|c|c|}
\hline $\begin{array}{c}\text { Sequence of } \\
\text { experiments }\end{array}$ & 2014 & 2015 & 2016 \\
\hline $1^{\text {st }}$ experiment & $\begin{array}{c}\text { Broad beans (vegetation pots } \\
\text { in outdoor conditions) }\end{array}$ & $\begin{array}{c}\text { Onions (vegetation pots in the } \\
\text { greenhouse) }\end{array}$ & - \\
\hline $2^{\text {nd }}$ experiment & - & $\begin{array}{c}\text { Broad beans (vegetation pots in } \\
\text { outdoor conditions) }\end{array}$ & $\begin{array}{c}\text { Onions (vegetation pots in } \\
\text { the greenhouse) }\end{array}$ \\
\hline
\end{tabular}

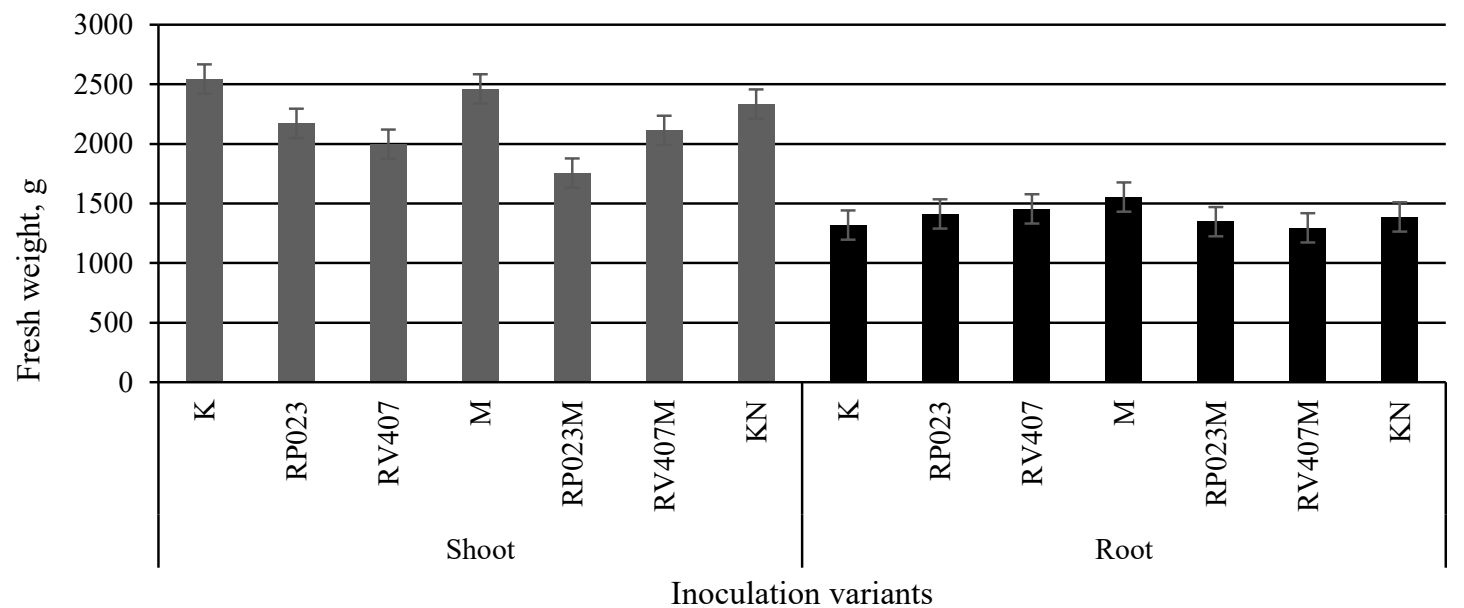

Figure 1. Shoot and root fresh weight from $1 \mathrm{~m}^{2}$ at the beginning of broad bean flowering (BBCH 60-61) in 2014.

the onion root system were calculated according to Brundrett et al. (1996).

The data were processed using ANOVA test and correlation analyses. The parameters were considered as significant at $\mathrm{p}<0.05$.

\section{Results and Discussion}

Shoot and root weight of the precrop. Broad beans is an important component for crop rotation. Therefore, in our experiment broad beans were used as the precrop for onions. Since beans were inoculated before sowing, used microorganisms could influence the following plants. Beans as the precrop affected mineral element quantity in soil - not only by symbiotically fixed nitrogen, but by post-harvest residue too. The differences between variants in shoot and root amount were found (Fig. 1).

The results showed that in year 2014 no significant differences between variants were detected $(\mathrm{p}=0.2$ and $p=0.9)$, but a tendency was found that inoculation with mycorrhiza preparation stimulated root growth. As a result, soil could reach more plant residue at the end of vegetation period. In year 2015 measurement of fresh weight of beans showed similar results with no statistically significant differences detected between variants (Fig. 2). However, a tendency remains that inoculated plants formed wider root system. This year plants inoculated with Rhizobium strain RP023 had more stimulated root system.

Yield of the subsequent crop. Influence of symbiotic microorganisms on plant depends on different environmental conditions, too. Therefore, the amount of plant residue, especially of roots, and amount and activity of symbiotic microorganisms are not similar every year. Survival and activity of microorganisms in the soil can affect not only nutrient availability, but can influence plant growth through activity of rhizosphere microorganisms. Comparison of onion leaf yield in 2015 and 2016 with control variant where precrop was not inoculated with microorganisms or fertilized with addition mineral nitrogen is shown in Figure 3.

In all variants, except variant where precrop was inoculated with Rhizobium strain RV407, the yield was higher than in the control variant. Moderate correlation between precrop root weight and subsequent crop yield was observed in 2015 when the correlation coefficient was 0.61 , but in 2016 it was 0.78 . Variant with additional nitrogen showed $12.4 \%$ and $14.3 \%$ higher yield than control variant, respectively.

Results showed that in both years leaves of onions grown in the control variant contained the highest dry matter content in comparison with treated ones (Table 3). The lowest dry matter content was detected 


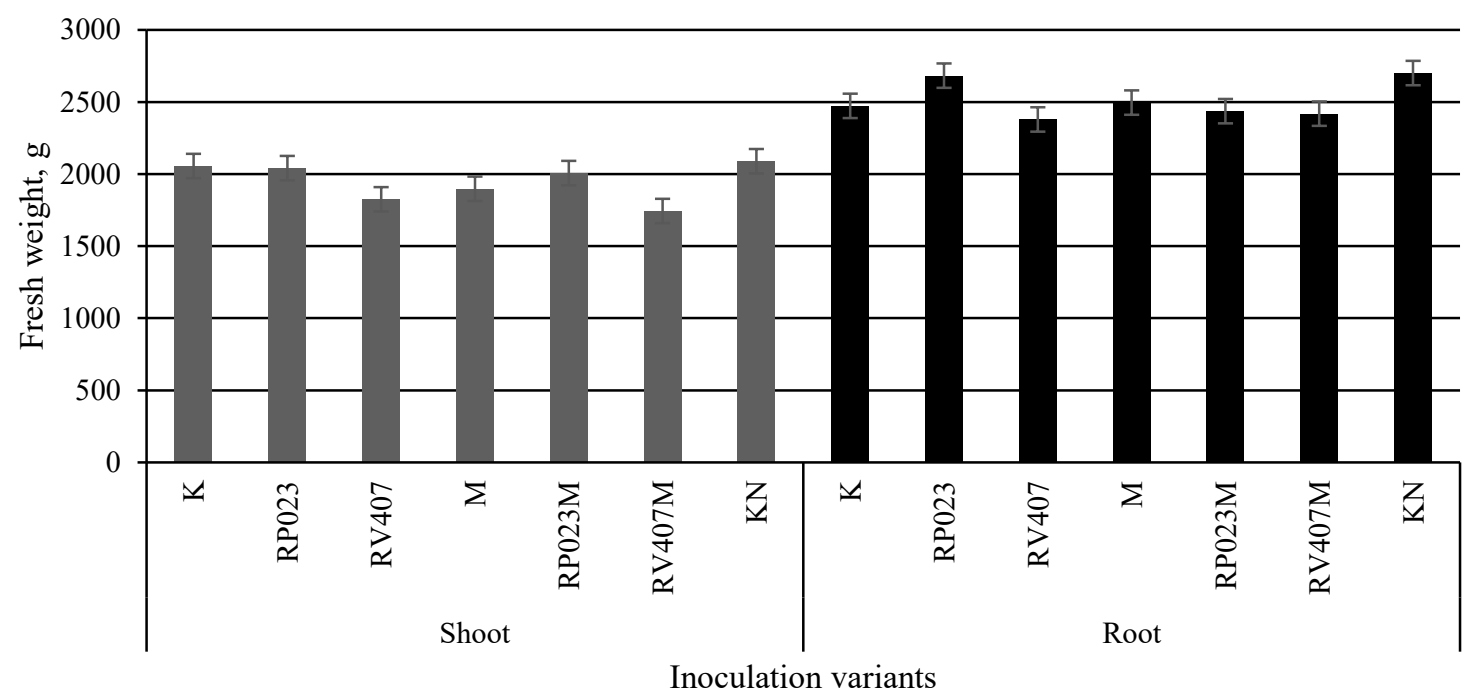

Figure 2. Shoot and root fresh weight from $1 \mathrm{~m}^{2}$ at the beginning of broad bean flowering (BBCH 60-61) in 2015.

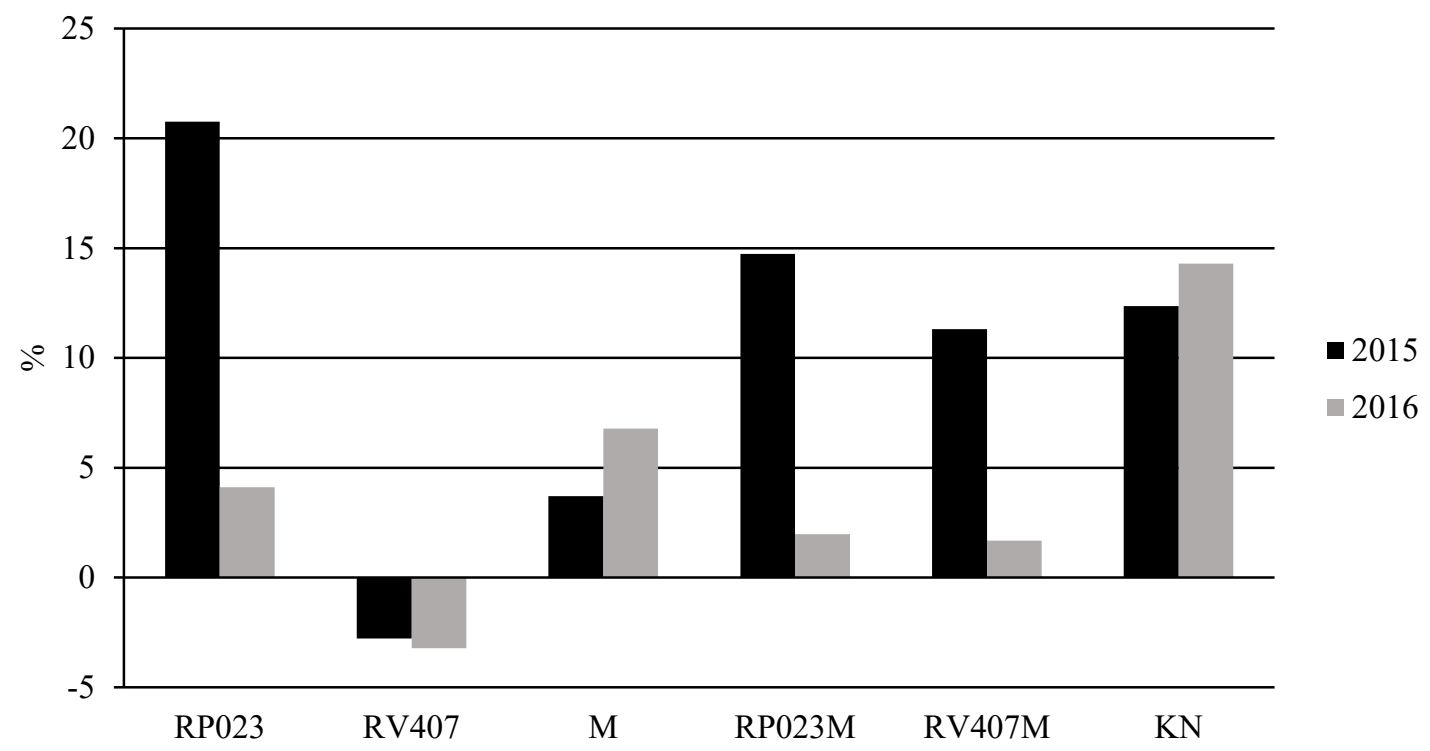

Figure 3. Onions leaf yield in experimental variants in comparison with control.

Average dry matter of onions leaves

Table 3

\begin{tabular}{|l|c|c|c|c|}
\hline \multirow{2}{*}{ Inoculation variants } & \multicolumn{2}{|c|}{ Year 2015 } & \multicolumn{2}{c|}{ Year 2016 } \\
\cline { 2 - 5 } & $\mathrm{mg} \mathrm{g}^{-1}$ & \% from control & $\mathrm{mg} \mathrm{g}^{-1}$ & \% from control \\
\hline K & 73.2 & 100.0 & 101.6 & 100.0 \\
\hline RP023 & 69.3 & 94.7 & 98.4 & 96.9 \\
\hline RV407 & 70.3 & 96.0 & 100.1 & 98.5 \\
\hline M & 68.0 & 92.9 & 93.8 & 92.3 \\
\hline RP023M & 70.9 & 96.8 & 98.9 & 97.3 \\
\hline RV407M & 71.9 & 98.2 & 99.1 & 97.5 \\
\hline KN & 71.9 & 98.2 & 97.9 & 96.3 \\
\hline
\end{tabular}


Mycorrhizal colonization of onions roots

\begin{tabular}{|l|c|c|c|c|c|}
\hline \multirow{2}{*}{ Mycorrhyzation parameters } & \multicolumn{5}{c|}{ Precrop inoculation variants } \\
\cline { 2 - 7 } & $\mathrm{K}$ & $\mathrm{M}$ & $\mathrm{RP023M}$ & $\mathrm{RV} 407 \mathrm{M}$ & $\mathrm{KN}$ \\
\hline Root fragments with mycorrhiza fungi & 152 & 180 & 166 & 180 & 176 \\
\hline Frequency of mycorrhiza in the root system, \% & 84.4 & 100 & 92.2 & 100 & 97.7 \\
\hline Abundance of arbuscules/ vesicules in root system, \% & 1.0 & 3.7 & 6.1 & 5.8 & 4.3 \\
\hline
\end{tabular}

in plants grown under mycorrhiza treatment. Variants treated with rhizobia strain RP023 in all cases had less dry matter in comparison with rhizobia strain RV407. Date elaboration approves significance of year's influence $\left(\mathrm{p}=5.22 \times 10^{-9}\right)$, as well as treatments influence $(\mathrm{p}=0.018)$.

At the end of the second year experiment, the onion root mycorrhiza colonization intensity was analysed. In all of the analysed root fragments from variants $(n=180)$ where precrop was inoculated, mycorrhiza fungi structures (fungal hyphae and arbuscules) were identified. Mycorrhiza fungi hyphae were detected also in the control variant, because soil contains indigenous fungi spores, however, in this variant the arbuscule abundance was low (Tab. 4). Higher abundance of arbuscules was detected in variants RP023M and RV407M $-6.1 \%$ and 5.8\%, respectively, suggesting that the plant establishes a functional symbiosis with the fungi. However, higher onion leaf yield in these variants was determined only in 2015. As pointed out by Rozpadek et al., (2016), arbuscule formation and colonization intensity differences often do not appear into phenotypic characteristics. At the same time Cavagnaro et al., (2015) stresses the importance of mycorrhiza fungi hyphae to limit mineral loss from the soil. This can explain the positive effect of mycorrhiza on plant growth.

Results of soil respiration intensity at the end of the experiment are summarized in Figure 4. The highest soil respiration intensity was determined in variants where more significant abundance of arbuscules/vesicules in onion roots was identified. It is an evidence of interaction between the plant and soil microorganisms. Similar results were shown by Zhang et al., (2016). They indicated that soil respiration intensity in the presence of mycorrhizal fungi is more intensive, but at the same time it is significantly influenced by environmental factors, especially soil moisture. Shi, Wang, \& Liu (2012) indicated that, in addition to abiotic factors, biotic factors are important as well, because the presence of AMF could enhance plant productivity and thus promote soil respiration. Soil respiration, which results from soil organic carbon decomposition, was determined by both soil microbial activity and substrate availability. However, it depends not only on the presence of VAM, but also on the interaction between different soil microorganisms (Shi, Wang, \& Liu, 2012). This is consistent with our results, where higher soil respiration was obtained in variants where

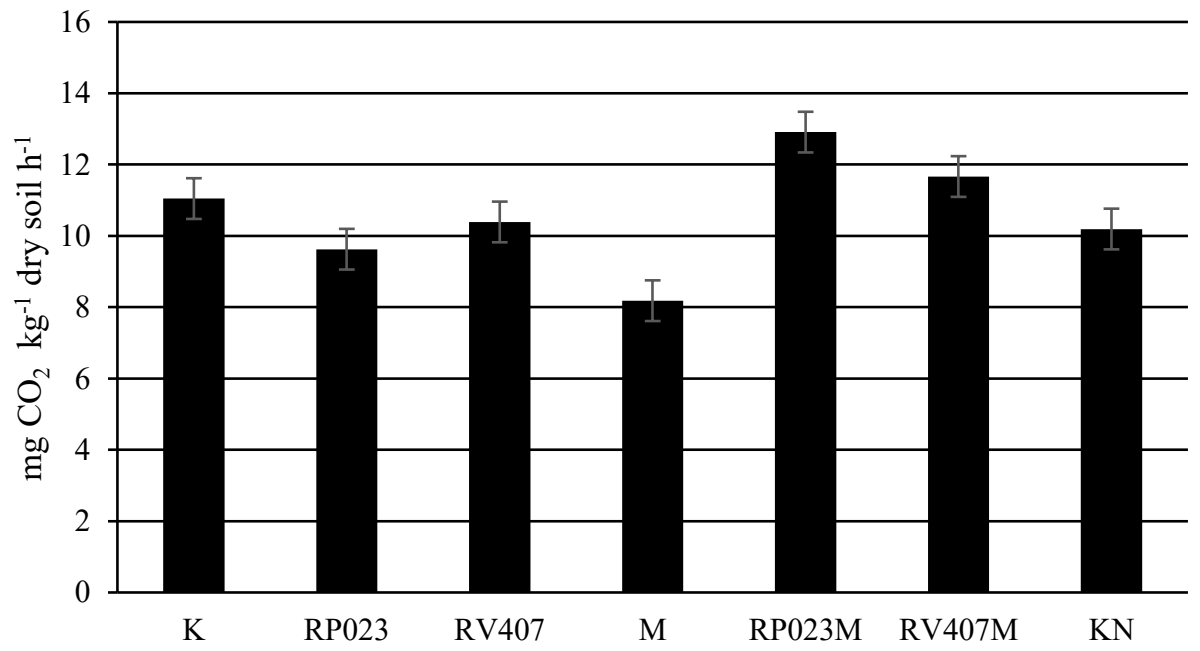

Figure 4. Soil respiration intensity at the end of experiment. 
double precrop inoculation was used. Cavagnaro et al., (2015) results show that AMF hyphae can promote the formation of soil macro-aggregates and reduce soil organic matter decomposition which affects growth conditions.

It can be summarized that crop rotation is recommended for onion cultivation. It was observed that precrop treatment with mineral nitrogen resulted in higher and more stable onion leaf yield. The effectiveness of microsymbiont treatment depended on the growing season. Better results with onion were obtained in 2015. It can be explained with the result of higher bean shoot yield in 2014 - on average $11 \%$ higher than in 2015 . In both years a small yield increase was observed also in variants with mycorrhiza. As pointed out by Cavagnaro et al. (2015), it could be explained by the enhanced precrop supply with water and mineral nutrition (mainly phosphorus). Variants with rhizobia treatment were variable and do not allow for any clear conclusions.

\section{Conclusions}

The use of microsymbionts for bean inoculation increased the subsequent crop (onion leaf) harvest by $9.5 \%$ in 2015 , and by $2.3 \%$ in 2016 . The impact of microsymbionts on the onion yield is variable, the highest yield increase was reached in 2015 under rhizobia strain RP023 treatment. Rhizobia strain RV407 gave a positive effect on the yield only in combination with mycorrhiza fungi. Precrop treatment with mineral nitrogen fertilizer increased the yield in both years - by 12.4 and $14.3 \%$ in 2015 and 2016, respectively. Under all treatments, dry matter content decreased in comparison with control. The highest incidence of mycorrhiza fungi structures was detected under mycorrhiza treatment, leading to a potentially improved subsequent plant yield. Tripartite symbiosis promoted soil respiration rate, which indicates a higher microorganism activity.

\section{Acknowledgement}

This research is supported by the 7th Research Framework Programme of the European Union project 613781, EUROLEGUME (Enhancing of legumes growing in Europe through sustainable cropping for protein supply for food and feed).

\section{References}

1. Abd-Alla, M.H., El-Enany, A.W.E., Nafady, N.A., Khlaf, D.M., \& Morsy, F.M. (2014). Synergistic interaction of Rhizobium leguminosarum bv. Viciae and arbuscular mycorrhizal fungi as a plant growth promoting biofertilizers for faba bean (Vicia faba L.) in alkaline soil. Microbiological Research, (169), 49 - 58. DOI: 10.1016/j.micres.2013.07.007.

2. Ames, R.N., \& Bethlenfalvay, G.J. (1987). Localized increase in nodule activity but no competitive interaction of cowpea rhizobia due to pre-establishment of vesicular-arbuscular mycorrhiza. New Phytologist, (106), $207-215$.

3. Brundrett, M., Bougher, N., Dell, B., Grove, T., \& Malajczuk, N. (1996). Working with Mycorrhizas in Forestry and Agriculture. AClAR Monograph.

4. Cavagnaro, T.R., Bender, S.F., Asghari, H.R., \& van der Heijden, V.A. (2015). The role of arbuscular mycorrhizas in reducing soil nutrient loss. Trends in Plant Science, (20), 283 - 290.

5. Hooker, J.E., \& Black, K.E. (1995). Arbuscular mycorrhizal fungi as components of sustainable soil-plant systems. Crit Rev Biotechnol. 15, 201 - 212. DOI: 10.3109/07388559509147408.

6. Koch, A.M., Croll, D., \& Sanders, I.R. (2006). Genetic variability in a population of arbuscular mycorrhizal fungi causes variation in plant growth. Ecology Letters, (9), 103 - 110. DOI: 10.1111/j.14610248.2005.00853.x.

7. Köpke, U., \& Nemecek, T. (2010). Ecological services of faba bean. Field Crop Research, 115, 217 - 233.

8. Munkvold, L., Kjøller, R., Vestberg, M., Rosendahl, S., \& Jakobsen, I. (2004). High functional diversity within species of arbuscular mycorrhizal fungi. New Phytologist164: 357 - 364. DOI: 10.1111/j.14698137.2004.01169.x.

9. Nuruzzaman, N.A., Lambers, H.A., Michael, D.A., Bolland, A.B., Erik, J., \& Veneklaas, A.C. (2005). Phosphorus uptake by grain legumes and subsequently grown wheat at different levels of residual phosphorus fertiliser. Australian Journal of Agricultural Research, 56, 1041 - 1047.

10. Ortas, I. (2010). Effect of mycorrhiza application on plant growth and nutrient uptake in cucumber production under field conditions. Spanish Journal of Agricultural Research, 8, 116 - 122.

11. Pell, M., Stenström, J., \& Granhall, U. (2005). Soil respiration. In: Bloem, J. et al. (Eds.), Microbiological methods for assessing soil quality, (pp. 117 - 126). UK, CPL Press.Preissel, S., Reckling, M., Schläfkea, N., \& Zander, P. (2015). Magnitude and farm-economic value of grain legume pre-crop benefits in Europe: A review. Field Crops Research, 175, $64-79$. 
12. Rozpadek, P., Rapała-Kozik, M., Wezowicz, K., Grandin, A., Karlsson, S., Wazny, R., Anielska, T., \& Turnau, K. (2016). Arbuscular mycorrhiza improves yield and nutritional properties of onion (Allium cepa). Plant Physiology and Biochemistry, 107, $264-272$.

13. Shi, Z., Wang, F., \& Liu, Y. (2012). Response of soil respiration under different mycorrhizal strategies to precipitation and temperature. Journal of Soil Science and Plant Nutrition, 12(3), $411-420$.

14. Shuab, R., Lone, R., Naidu J., Sharma, V., Imtiyaz S., \& Koul, K. (2014). Benefits of Inoculation of Arbuscular Mycorrhizal Fungi on Growth and Development of Onion (Allium cepa) Plant. AmericanEurasian J. Agric. \& Environ. Sci., 14(6), 527 - 535. DOI: 10.5829/idosi.aejaes.2014.14.06.12347.

15. Stagnari, F., Maggio, A., Galieni, A., \& Pisante, M. (2017). Multiple benefits of legumes for agriculture sustainability: an overview. Chem. Biol. Technol. Agric. 4(2), 1 - 13, DOI: 10.1186/s40538-016-0085-1.

16. Sturz, A.V., \& Christie, B.R. (2003). Beneficial microbial allelopathies in the root zone: the management of soil quality and plant disease with rhizobacteria. Soil and Tillage Research, 72, $107-123$.

17. Heijden van der, M.G.A., \& Scheublin, T.R. (2007). Functional traits in mycorrhizal ecology: their use for predicting the impact of arbuscular mycorrhizal fungal communities on plant growth and ecosystem functioning. New Phytologist, 174, $244-250$.

18. Verbruggen, E., \& Kiers, T. (2010). Evolutionary ecology of mycorrhizal functional diversity in agricultural systems. Evolutionary Applications, 3, 547 - 556. DOI: 10.1111/j.1752-4571.2010.00145.x.

19. Vierheilig, H., Coughlan, A.P., Wyss, U., \& Piche, Y. (1998). Ink and Vinegar, a Simple Staining Technique for Arbuscular-Mycorrhizal Fungi. Applied and Environmental Microbiology. 64 (12), 5004 - 5007.

20. Zhang, B., Li, S., Chen, S., Ren, T., Yang, Z., Zhao, H., Liang, Y., \& Han, X. (2016). Arbuscular mycorrhizal fungi regulate soil respiration and its response to precipitation change in a semiarid steppe. Scientific Reports. 6, Article number: 19990. DOI: 10.1038/srep19990. 